\title{
Redenen voor verzuim door studenten na vrijwillige inschrijving voor simulatiepatiëntencontacten
}

\author{
K. te Sligte, J. van Dalen, G.M. Verwijnen, J.-J. Rethans
}

\begin{abstract}
Samenvatting
Het Medisch Praktisch Onderwijs (MPO) is een belangrijk onderdeel van het curriculum van de Faculteit der Geneeskunde van de Universiteit Maastricht. In het MPO worden studenten getraind in communicatievaardigheden die toegepast worden bij het afnemen van de anamnese en uitvoeren van lichamelijk onderzoek. Studenten worden zich ook bewust van hun eigen attitude. Een belangrijk onderdeel van het MPO zijn de individuele contacten met simulatiepatiënten. Studenten kunnen zich vrijwillig inschrijven voor deze onderwijsactiviteit. Inschrijving verplicht echter tot deelname. In dit artikel zijn de verzamelde gegevens over de simulatiepatiëntencontacten en het verzuim daarbij in curriculumjaar 1999/2000 beschreven. Er is onder andere gekeken naar de redenen die studenten voor hun verzuim opgeven. Studenten zijn meestal afwezig door eigen slordigheid en nalatigheid en vaak is de reden onbekend. Derde- en vierdejaars schrijven zich minder vaak in en zijn ook vaker afwezig. De meeste studenten zijn maar één keer afwezig. In de laatste onderwijsperiode is de afwezigheid duidelijk groter dan in voorgaande periodes. (Sligte K te, Dalen J van, Verwijnen $G M$, Rethans J-J. Redenen voor verzuim door studenten na vrijwillige inschrijving voor simulatiepatiëntencontacten. Tijdschrift voor Medisch Onderwijs 2001;20(5):214-219.)
\end{abstract}

\section{Inleiding}

Een belangrijk onderdeel van het huidige curriculum van de Faculteit der Geneeskunde van de Universiteit Maastricht wordt gevormd door het Medisch Praktisch Onderwijs (MPO). De coördinatie van dit onderwijs vindt plaats in het Skillslab. Studenten schrijven zich aan het begin van het jaar in voor een MPO-groep. Deze groepen van tien studenten en één of twee docenten hebben ongeveer twee keer per blok een onderwijsbijeenkomst. In het MPO worden studenten getraind in het integreren van communicatie- en medische vaardigheden. Daarbij wordt aandacht besteed aan attitudeontwikkeling. ${ }^{1}$ In dit onderwijs wordt voornamelijk gebruik gemaakt van contacten met simulatiepatiënten. De student krijgt minimaal vijf keer per jaar de kans individueel een compleet consult te voeren met een getrainde simulatiepatiënt in daarvoor speciaal in- gerichte spreekkamers. ${ }^{2} \mathrm{Bij}$ deze contacten is in principe altijd een medestudent aanwezig uit dezelfde MPO-groep. Deze medestudent functioneert als observator en kan direct feedback geven tijdens en na het gesprek. Ieder simulatiepatiëntencontact (SPC) wordt op videoband opgenomen. Begeleider(s) en groepsleden van de MPO-groep bekijken de videoband later. In een volgende MPO-bijeenkomst wordt het consult nabesproken.

Studenten kunnen zich in duo's vrijwillig voor een SPC inschrijven. Inschrijving verplicht echter wel tot deelname. Studenten die zich ingeschreven hebben, maar verhinderd zijn en niet op het geplande tijdstip aanwezig kunnen zijn, dienen zich af te melden. Dit kan op verschillende manieren: mondeling, telefonisch of per e-mail via het secretariaat van het Skillslab of via de verantwoordelijke student-assistent. De student-assis- 
tent is een derde- of vierdejaars geneeskundestudent, aangesteld door het Skillslab, die aanwezig is op dagen dat er SPC's gepland zijn. De student-assistent fungeert als 'doktersassistent' en kan onder andere gegevens van lichamelijk onderzoek verstrekken die niet te simuleren zijn. Studenten kunnen bij de studentassistent terecht met inhoudelijk vragen over het SPC, bijvoorbeeld wanneer ze in hun gesprek vast komen te zitten. Bovendien zijn de student-assistenten verantwoordelijk voor de registratie van aanen afwezige studenten. Afmeldingen van studenten binnen 48 uur voor het begin van het SPC waarvoor ze zich hebben ingeschreven, worden alleen geaccepteerd in geval van nood of overmacht. De reden hiervoor is dat er op dat tijdstip in mankracht en ruimte is geïnvesteerd. Bij zeer late afmelding kunnen deze niet meer worden benut ten behoeve van andere studenten. Studenten die afwezig zijn zonder zich afgemeld te hebben, ontvangen een 'boze' brief van de coördinator van het MPO. Hierin wordt hun gevraagd contact op te nemen om de reden voor hun verzuim toe te lichten. Studenten zijn uitgesloten van verdere deelname aan (volgende) SPC's, als zij zich niet melden.

Het aantal studenten dat zonder iets van zich te laten horen een SPC verzuimde in curriculumjaar 1999/2000, leek groot. Het riep irritaties op bij simulatiepatiënten, medestudenten en betrokken medewerkers. Daarnaast werden onnodig ruimtes, tijd en simulatiepatiënten gereserveerd. Hierdoor ontstond de behoefte de gegevens over het verzuim bij SPC's te inventariseren. De volgende vragen speelden daarbij een rol. Hoeveel contacten zijn er geweest in curriculumjaar 1999/2000? Hoe vaak kwam het voor dat een student afwezig was bij een contact? Waarom verzuimden studenten, ondanks vrijwillige inschrijving, welke redenen hadden ze hiervoor? Bij andere trainingen op het Skillslab is de aanwezigheid van eerstejaars studenten hoger dan die van vierdejaars. ${ }^{3}$ Waren er ook zulke verschillen tussen jaargroepen bij de SPC's? Was er misschien sprake van bepaalde 'probleemstudenten', die vaak afwezig waren? Bekend is dat de opkomst bij vaardigheidstrainingen op het Skillslab afneemt in de loop van het jaar. Was dit ook het geval bij de contacten met simulatiepatiënten? ${ }^{3}$

\section{Methode}

Omdat deze vragen pas gaandeweg het curriculumjaar gesteld werden en de resultaten eventueel bruikbaar waren voor het volgende curriculumjaar 2000/2001, werd gekozen voor een retrospectief, exploratief onderzoek. Hierdoor kon niet worden voorkomen dat bepaalde gegevens onvolledig waren. Er werd gebruik gemaakt van de inschrijflijsten voor de SPC's in het curriculumjaar 1999/2000. Dit zijn formulieren waarop studenten zelf hun naam genoteerd hadden. Hiermee kon het aantal inschrijvingen voor SPC's geteld worden en vergeleken met het aantal door het Skillslab aangeboden mogelijkheden. Afwezige studenten waren gedurende het jaar met naam geregistreerd door de student-assistenten SPC. Dit betrof zowel studenten die zich afgemeld hadden, als de studenten die verzuimd hadden zich af te melden en vervolgens een 'boze' brief ontvangen hadden. De namen van deze laatste groep studenten werden ook gemeld aan het hoofd van het Skillslab van de Faculteit der Geneeskunde van de Universiteit Maastricht. Om de reden van de afwezigheid te achterhalen werd gebruik gemaakt van antwoordbrieven, afgegeven door de coördinator MPO, bij wie studenten zich gemeld hadden om hun verzuim toe te lichten. In deze brieven stond de reden 
voor het niet afmelden. De studenten moesten deze brieven inleveren bij de student-assistenten als zij mee wilden doen bij een volgend SPC.

\section{Resultaten}

Bij inventarisatie van de gegevens bleek dat er twee inschrijflijsten (66 SPC's) verloren waren gegaan en dat niet alle antwoordbrieven bewaard waren gebleven. In het curriculumjaar 1999/2000 zijn in het Skillslab 3060 contacten met simulatiepatiënten aangeboden aan studenten uit de eerste vier jaar van de studie geneeskunde. Dit betreft de contacten die door hadden kunnen gaan. Dit aantal ligt iets lager dan het aantal geplande contacten, vanwege onverwachte verhindering van simulatiepatiënten, door bijvoorbeeld ziekte. In jaar drie en vier zijn er ook enkele spreekuursimulaties geweest. Hierin kreeg één student meerdere simulatiepatiënten achter elkaar te zien. Besloten is om dit toch als één SPC te rekenen. De studenten hebben zich ingeschreven voor 2703 contacten en hebben dus niet van alle aangeboden mogelijkheden gebruik gemaakt. Wanneer dit uitgesplitst wordt naar de verschillende jaargroepen, dan valt op dat studenten zich minder in-

Tabel 1. Gegevens over simulatiepatiëntencontacten in 1999/2000 per studiejaar: het aantal aangeboden contacten, het aantal contacten waarvoor door studenten is ingeschreven en het percentage studenten dat zich heeft ingeschreven.

\begin{tabular}{lccc}
\hline & $\begin{array}{c}\text { Aangeboden } \\
\text { contacten (N) }\end{array}$ & $\begin{array}{c}\text { Ingeschreven } \\
\text { contacten (N) }\end{array}$ & $\begin{array}{c}\text { Inschrijving } \\
\text { studenten (\%) }\end{array}$ \\
\hline Jaar 1 & 645 & 601 & 93.2 \\
Jaar 2 & 1029 & 936 & 91.0 \\
Jaar 3 & 813 & 688 & 84.6 \\
Jaar 4 & $573^{*}$ & $478^{*}$ & 83.4 \\
Totaal jaar 1 t/m 4 & 3060 & 2703 & 88.3 \\
Gemiddelde jaar 1 t/m 4 & & & 8 \\
\hline
\end{tabular}

* 2 inschrijflijsten zijn verloren gegaan, waardoor de exacte getallen niet te achterhalen zijn. Aangenomen is dat op deze lijsten 66 contacten zijn aangeboden en dat er voor al deze contacten is ingeschreven.

Tabel 2. Gegevens per studiejaar voor 1999/2000 over SPC's waarbij een student die zich ingeschreven had, niet aanwezig was.

\begin{tabular}{lccc}
\hline & \multicolumn{3}{c}{ Aantal contacten waarbij een student afwezig was } \\
\cline { 2 - 4 } & $\begin{array}{c}\text { Met afmelding } \\
(\mathrm{N})\end{array}$ & $\begin{array}{c}\text { Zonder afmelding } \\
(\mathrm{N})\end{array}$ & $\begin{array}{c}\text { Totaal } \\
(\mathrm{N})\end{array}$ \\
\hline Jaar 1 & 22 & 34 & 56 \\
Jaar 2 & 30 & 25 & 55 \\
Jaar 3 & 55 & 47 & 102 \\
Jaar 4 & 44 & 23 & 67 \\
Totaal & 151 & 129 & 280 \\
\hline
\end{tabular}


Tabel 3. Redenen van onafgemelde afwezigheid bij SPC's in 1999/2000. Per studiejaar wordt de frequentie aangegeven waarmee de verschillende redenen door onafgemeld afwezige studenten zijn genoemd.

\begin{tabular}{lccccc}
\hline & Jaar 1 & Jaar 2 & Jaar 3 & Jaar 4 & Totaal \\
\hline Vergeten & 10 & 1 & 2 & 1 & 14 \\
Dubbele inschrijving & 1 & 8 & 3 & 2 & 14 \\
Niet (juist) in agenda & 5 & 4 & 5 & 0 & 14 \\
Misverstand met partner* & 6 & 2 & 6 & 0 & 14 \\
Sterfgeval in familie & 1 & 0 & 1 & 0 & 2 \\
Ziek & 4 & 2 & 4 & 2 & 12 \\
Onbekend & 7 & 8 & 26 & 18 & 59 \\
Totaal & 34 & 25 & 47 & 23 & 129 \\
\hline
\end{tabular}

* met partner wordt bedoeld de student die zich samen met de afwezige student had ingeschreven.

Tabel 4. Aantal studenten dat onafgemeld afwezig was bij een SPC in 1999/2000, uitgesplitst naar frequentie van onafgemelde afwezigheid.

Aantal studenten

(N)

SPC verzuim: 1 keer

112

SPC verzuim: 2 keer

7

SPC verzuim: 3 keer

1

Totaal

120

schrijven naarmate hun studie vordert (tabel 1).

Bij 280 van deze 2703 contacten was een student afwezig. Bij 129 van deze 280 contacten liet de student niets van zich horen. Deze studenten hebben dus een 'boze' brief ontvangen. Tabel 2 geeft een overzicht van de aantallen gemiste contacten met en zonder afmelding door de student. Wanneer dan wordt gekeken naar de verschillende jaargroepen, valt op dat vierdejaars studenten zich bij afwezigheid vaker afmelden.

De redenen die de studenten met een 'boze' brief doorgaven aan de coördinator
MPO, konden in zeven categorieën worden ingedeeld, aan de hand van de antwoordbrieven (tabel 3). Hierbij is een restcategorie 'onbekend' gecreëerd voor de studenten van wie zeker is dat zij een 'boze' brief ontvangen hebben, maar die zich nooit gemeld hebben bij de coördinator MPO en hun reden dus nooit kenbaar hebben gemaakt. Dubbele inschrijving wil zeggen dat de studenten tweemaal met naam vermeld waren op de inschrijflijsten bij een zelfde SPC-rol en slechts één keer kwamen. Meer dan één keer inschrijven op de lijsten is niet toegestaan.

Er werd tevens nagegaan of bepaalde studenten vaker dan één keer onafgemeld verzuimden en dus meer dan één 'boze' brief ontvingen. Tabel 4 laat zien dat er van echte 'probleemstudenten' geen sprake was.

Het verzuim van studenten kan ook worden uitgesplitst naar de verschillende blokken, om verschillen in de loop van het jaar te bekijken. Om dit te beoordelen werd het aantal studenten dat in hun laatste blok verzuimde, afgezet tegen het gemiddelde aantal verzuimde contacten per blok in de voorafgaande blokken (tabel 5) 
Tabel 5. Vergelijking tussen het verzuim in het laatste onderwijsblok en het gemiddelde verzuim in de voorgaande blokken in 1999/2000. De SPC's waren verspreid over 4 reguliere onderwijsblokken in jaar 1 en 4 en over 6 blokken in jaar 2 en 3.

\begin{tabular}{ccc}
\hline & $\begin{array}{c}\text { Gemiddelde verzuim } \\
\text { per blok (N) }\end{array}$ & $\begin{array}{c}\text { Verzuim in } \\
\text { laatste blok (N) }\end{array}$ \\
\hline Jaar 1 & 8 & 10 \\
Jaar 2 & 3 & 12 \\
Jaar 3 & 6 & 15 \\
Jaar 4 & 4 & 12 \\
\hline
\end{tabular}

\section{Discussie}

Aan het begin van het onderzoek waren de gegevens omtrent het verzuim van studenten bij contacten met simulatiepatiënten op het Skillslab nog niet eerder gekwantificeerd en gekwalificeerd. We wisten van tevoren niet precies wat we konden verwachten. Het retrospectieve gebruik van schriftelijke gegevens laat niet toe dat er glasharde conclusies getrokken worden. Het geeft echter wel een duidelijk beeld van de situatie die tot op heden onbekend was.

Contacten met simulatiepatiënten zijn een vrijwillige onderwijsactiviteit en een gemiddeld inschrijvingspercentage voor alle vier studiejaren van bijna negentig is een erg goed resultaat. ${ }^{4}$ Zoals verwacht, schreven met name eerste- en tweedejaars zich goed in voor deze contacten. Bij de ouderejaars was het animo iets minder.

Een nadeel van de gebruikte retrospectieve methode is dat de diverse gegevens niet altijd met elkaar te vergelijken waren. Zo zijn de gegevens in tabel 1 uitgedrukt in aantallen contacten, dat wil zeggen het aantal mogelijkheden voor een SPC, waar één à twee studenten gelijktijdig aan deelnemen, één als arts en één als observator. De gegevens over het verzuim zijn echter uitgedrukt in aantallen studenten, waarbij geen onderscheid gemaakt kon worden tussen 'artsen' en 'observatoren'. Een 'observator' kan bij afwezigheid van de 'arts' diens rol overnemen en zelf het SPC doen. Er kan dus niet gezegd worden of een afwezige student ook automatisch leidde tot een gemist contact waarbij een simulatiepatiënt en spreekkamer onnodig gereserveerd waren.

Uit tabel 3 komt naar voren dat een groot gedeelte van het verzuim veroorzaakt wordt door slordigheid en nalatigheid van de studenten (vergeten, dubbele inschrijving, niet juist in agenda, misverstand met partner). Dit betrof 56 van de 129 gemiste contacten waarbij een student zich niet had afgemeld. In de meeste gevallen van verzuim is er dus geen sprake van een noodgeval of overmacht. Daarnaast is een groot deel van de redenen onbekend. Studenten lijken niet altijd gemotiveerd om hun verzuim toe te lichten en zouden zichzelf dus vrijwillig uitsluiten van deelname aan een volgend SPC. Bij navraag bleek echter, dat deze studenten ook zonder antwoordbrief toegelaten werden tot een volgend SPC. Studenten werden vaak niet gedwongen hun reden kenbaar te maken door onvolledig en inconsequent toepassen van de regels. De regels moesten gehanteerd worden door de student-assistenten, die er moeite mee hadden zich hard op te stellen ten opzichte van hun medestudenten.

In het kader van medisch professioneel gedrag kan het misschien van belang zijn de groep studenten van wie de reden voor afwezigheid onbekend is, kleiner te maken. ${ }^{5}$ Hiertoe zijn er voor curriculumjaar 2000/2001 een aantal kleine veranderingen aangebracht. Ten eerste is de afmeldingsprocedure (ongewijzigd) beter bekendgemaakt onder de studenten, maar ook onder de begeleiders van de MPOgroepen, die de studenten moeten beoordelen op hun medisch professioneel ge- 
drag. Dit is gedaan door middel van schriftelijk vermelden van de procedure op diverse plaatsen, onder andere in de studenteninformatie van het blokgebonden onderwijs, bij de spreekkamertjes van SPC en bij het secretariaat van het Skillslab. Ook is in de eerste MPO-bijeenkomst van het jaar de procedure mondeling besproken door de begeleider(s) van de groep. Daarnaast is de registratie van afwezige studenten uitgebreid en zijn er afspraken gemaakt over het zo consequent mogelijk toepassen van de regels door de student-assistenten. Hiermee hopen we de categorie 'reden onbekend' zo klein mogelijk te maken, waardoor misschien volgend jaar bekeken kan worden of er verdere stappen ondernomen moeten en kunnen worden om het verzuim terug te dringen.

\section{Literatuur}

1. Dalen J van, Bartholomeus P, Kerkhofs E, Lulofs $\mathrm{R}$, Thiel J van, Rethans J-J, et al. Teaching and assessing communication skills in Maastricht; the first twenty years. Med Teach 2001 (in press).

2. Gorter SL, Rethans J-J, Scherpbier AJJA. De rol van (simulatie)patiënten in het onderwijs. Tijdschrift voor Medisch Onderwijs 2000;19:42-8.
3. Scherpbier AJJA, Kerkhofs E, Verhoeven BH, Gerwen ALEM van, Wolfhagen HAP, Vleuten CPM van der. Trends in aanwezigheid bij het vaardigheidsonderwijs. Bulletin Medisch Onderwijs 1998;17:143-8.

4. Kerkhofs EEM, Jansvedel LAT, Scherpbier AJJA, Dalen J van, Havas J, Kruseman H, et al. Het volgen van een training gynaecologisch en/of andrologisch onderzoek: kenmerken van wel- en nietdeelnemende studenten. Tijdschrift voor Medisch Onderwijs 2000;19:191-7.

5. Luijk SJ van, Santen-Hoeufft M van, Hillen HFP, Smeets JGE. Het beoordelen van professioneel gedrag bij studenten en artsen. Tijdschrift voor Medisch Onderwijs 2000;19:163-71.

\section{De auteurs:}

K. te Sligte, vierdejaars geneeskundestudent, student-assistent Skillslab, Faculteit der Geneeskunde, Universiteit Maastricht.

J. van Dalen, psycholoog, medewerker Skillslab, Faculteit der Geneeskunde, Universiteit Maastricht.

G.M. Verwijnen, arts, hoofd Skillslab, Faculteit der Geneeskunde, Universiteit Maastricht.

J.-J. Rethans, huisarts, medewerker Skillslab, Faculteit der Geneeskunde, Universiteit Maastricht.

Correspondentieadres:

J.-J. Rethans, Skillslab, Universiteit Maastricht, Postbus 616, 6200 MD Maastricht, tel.: 043-3881790, J.Rethans@sk.unimaas.nl.

\section{Summary}

Medical Practical Education (MPE) is an important component of the curriculum of the Faculty of Medicine of the University of Maastricht. Simulated Patient Contacts (SPCS) are used in MPE for communication and clinical skills training, and the development of a professional attitude. SPCs are not obligatory and students are free to register for this activity. However, once a student has registered, attendance is mandatory. This article contains a description of the data collected in 1999/2000 on SPCS and the non-attendance of students who registered for SPC. Special attention is given to the reasons students give for their absence. Most students failed to attend due to their own negligence. In many cases, no reason was provided. Third and fourth year students registered in smaller numbers and were absent more often. Most students were absent only once. In the final period of the year there were more non-attenders than in the previous periods. (Sligte K te, Dalen J van, Verwijnen GM, Rethans J-J. Why do students fail to attend simulated patient contacts despite voluntary registration? Dutch Journal of Medical Education 2001;20(5):214-219.) 